\title{
DILEMAS NA IMPLANTAÇÃO DA EDUCAÇÃO SUPERIOR PÚBLICA EM UMA IFES NA AMAZÔNIA
}

\author{
Francisca Márcia Lima de Sousa \\ Anselmo Alencar Colares
}

\section{Resumo}

Os desafios educacionais para a efetivação da educação escolar são diversificados e exigem esforço coletivo para serem compreendidos. Esse estudo trata de alguns dos dilemas que estiveram presentes no processo de implantação do curso de pedagogia em Santarém, cidade localizada no interior da Amazônia brasileira. Traz uma abordagem histórica das primeiras ações da Universidade Federal do Pará (UFPA), durante a década de 1970, fora da capital, onde o curso havia sido implantado, ainda na década de 1950. Contextualiza as ações extensionistas e de ensino daquela Instituição Federal de Ensino Superior (IFES) relativas à formação de professores, como um dos mais instigantes desafios na/da região de atuação da UFPA. O curso de pedagogia foi uma espécie de desbravador da interiorização do ensino superior público em Santarém e em outros locais da região. No caso do município objeto desse estudo, representa o mais importante precedente histórico da criação da Universidade Federal do Oeste do Pará (UFOPA), a primeira instituição de ensino superior federal criada fora de uma das capitais da Amazônia.

Palavras chave: educação superior; formação de professores; história da educação; Amazônia.

\section{DILEMMAS IN THE IMPLEMENTATION OF PUBLIC HIGHER EDUCATION IN AN IFES IN THE AMAZON}

\begin{abstract}
The educational challenges for implementing school education are diverse and require collective effort to be understood. This study addresses some of the dilemmas that were presented in the process of implementing the pedagogy course in Santarém, a city located in the interior of the Brazilian Amazon. It brings a historical approach to the first actions of the Federal University of Pará (UFPA), during the 1970s, outside the capital, where it had been implemented in the 1950s. Contextualizing the extension and educational actions of that Federal Institution of Higher Education (IFES) related to teacher training, as one of the most exciting challenges in / of the region where UFPA operates. The pedagogy course was a kind of pioneer in the interiorization of public higher education in Santarém and other places in the Region. And in the case of the city object of this study, it represents the most important historical precedent for the creation of the Federal University of Western Pará (UFOPA), the first federal higher education institution created outside of the capitals of the Amazon.
\end{abstract}

Keywords: college education; teacher training; education history; Amazon.

\section{DILEMAS EN LA APLICACIÓN DE LA EDUCACIÓN PÚBLICA SUPERIOR EN UN IFES EN LA AMAZONAS}

Resumen

Los desafíos educativos para implementar la educación escolar son diversos y requieren un esfuerzo colectivo para ser entendidos. Este estudio aborda algunos de los dilemas que estuvieron presentes en el proceso de implementación del curso de pedagogía en Santarém, una ciudad ubicada en el interior de la Amazonía brasileña. Aporta un enfoque histórico a las primeras acciones de la Universidad Federal de Pará (UFPA), durante la década de 1970, fuera de la capital, donde se había implementado en la década de 1950. Contextualizando la extensión y las acciones educativas de esa Institución Federal de Educación Superior 
(IFES) relacionado con la capacitación de docentes, como uno de los desafíos más emocionantes en / en la región donde opera UFPA. El curso de pedagogía fue una especie de pionero en la interiorización de la educación superior pública en Santarém y otros lugares de la Región. Y en el caso del municipio objeto de este estudio, representa el precedente histórico más importante para la creación de la Universidad Federal del Oeste do Pará (UFOPA), la primera institución federal de educación superior creada fuera de una de las capitales de la Amazonas.

Palabras clave: educación universitaria; formación de profesores; historia de la educación; Amazonas.

\section{INTRODUÇÃO}

As Instituições de Ensino Superior (IES) têm por desafio e compromisso produzir conhecimentos. Desde aqueles que são chamados básicos, teóricos, ou especulativos, até os que se voltam para a aplicação concreta contribuindo, por exemplo, para transformar os recursos naturais em ganhos socioeconômicos. Isto se dá de maneira ambientalmente sustentável (o que seria desejável), ou não, mas, fundamentalmente articulado à ciência, à tecnologia e aos processos de difusão que as institucionais educacionais realizam cotidianamente.

$\mathrm{Na}$ perspectiva "quase" utópica, defendida por estudiosos e entidades do campo educacional, nutre-se um projeto de universidade pública / estatal gratuita, laica, democrática e acessível a todas as classes sociais. Constitui-se, assim, não apenas um "[...] lugar de produção, sistematização e disseminação do conhecimento" (SEVERINO, 2008, p. 75) mas, também, um espaço inclusivo, dotado de um padrão unitário e inseparável entre ensino, pesquisa e extensão que, além de se ocupar das questões relativas ao desenvolvimento e aos problemas que afetam os setores da vida material, ainda provoque manifestações como: a expressão da arte, a interação entre culturas, o diálogo e a mediação da cidadania e da democracia.

Assim, faz-se necessário que as IES estejam presentes nos mais diferenciados locais. Entretanto, a história da educação superior brasileira (ROMANELLI, 2002; SEVERINO, 2009) demonstra que a presença da universidade por muito tempo foi centralizada nas capitais e grandes centros urbanos. Até o final da década de 1970, as universidades públicas localizadas na região amazônica concentraram suas atividades nas capitais, de forma isolada. Somente a partir da década de 1980, ainda muito timidamente, passaram a buscar alternativas para o desenvolvimento científico e tecnológico da Amazônia, de maneira articulada (ARAGÓN, 2001).

Muitos são os desafios para se promover a educação superior em um contexto de singularidades como a Amazônia, onde a produção de conhecimento científico é incipiente, no geral, e mais ainda no que diz respeito ao campo educacional, o qual apresenta problemas e também soluções que ainda permanecem em grande parte desconhecidos. Por essa razão, entende-se que o registro e a divulgação de iniciativas exitosas, como essa que ora será apresentada, contribuem para o aprimoramento das ações, possibilitando correções de problemas sem repetir erros, bem como aprimorar os acertos, ou pelo menos evitar que haja retrocessos.

Para o levantamento das informações de natureza histórica, foram realizadas entrevistas com gestores e professores que fizeram parte dos acontecimentos relatados. As falas foram cotejadas com outras fontes, por meio da pesquisa documental (com a compreensão alargada de documento, para além dos oficiais, como por exemplo publicações de jornais e registros obtidos em arquivos pessoais), assim como de trabalhos elaborados na modalidade de pesquisa acadêmica. Metodologicamente, buscou-se compreender os acontecimentos, tendo em vista as relações entre o singular e o universal, os grupos e seus respectivos interesses em disputa, razão pela qual não se tornou relevante a análise dos discursos em si, mas como eles se articularam com as ações desencadeadas e que resultaram na oferta, mesmo incipiente, da educação superior em Santarém, 
cidade localizada a cerca de $850 \mathrm{~km}$ de Belém e $810 \mathrm{~km}$ de Manaus, as duas principais capitais da Amazônia. Fundada em 1661 pelo padre João Felipe Bettendorf, como missão jesuítica, tornou-se vila em 1758 e foi elevada à categoria de cidade em 24 de outubro de 1848. Tornou-se referência na região Oeste do Pará e o segundo município em importância política no estado. Hoje conta com a presença de diversas IES públicas e privadas, e um número superior a 50 cursos, sendo que a Universidade Federal do Oeste do Pará (UFOPA), criada no final de 2009, responde por cerca de 30 deles e atende a aproximadamente 8 mil estudantes, incluindo indígenas e quilombolas que ingressam por meio de processo seletivo diferenciado. A UFOPA foi oriunda da fusão de dois campi universitários existentes em Santarém: o da Universidade Federal do Pará (UFPA) e o da Universidade Federal Rural da Amazônia (UFRA), cujas origens são marcadas por sonhos, lutas, resistências, frustrações e êxitos. Parte dessa história será tratada nas páginas a seguir, tendo como eixo condutor da narrativa a implantação do curso de pedagogia, no Núcleo, posterior Campus Universitário da UFPA.

O artigo está organizado em três tópicos, considerando os principais desafios identificados quanto à implantação e desenvolvimento da educação superior pública nesta parte da Amazônia.

\section{O DESAFIO DE SAIR DA CAPITAL PARA O INTERIOR}

As primeiras ações que denotam a presença da UFPA em um município fora da capital aconteceram duas décadas após a sua criação. No período de 1971 a 1973, ofertou cursos de licenciatura autorizados por meio do Parecer n. 663/1970, do Conselho Federal de Educação (CFE); e da Resolução n. 39/1970, do Conselho Universitário (Consun/UFPA), que permitiram a criação do Núcleo de Educação em Santarém, em 14 de outubro de 1970. O referido Núcleo foi instalado na Escola Estadual Álvaro Adolfo da Silveira e representou a primeira experiência de interiorização da UFPA, cuja atuação era restrita à capital do estado.

No dia 22 de dezembro de 1970 foi oficialmente inaugurado, em Santarém, o Núcleo de Educação da Universidade Federal do Pará, com a presença do então Reitor, Aloysio da Costa Chaves e do Diretor do Centro de Educação, professor Antônio Gomes Moreira. No dia 02 de janeiro de 1971 os jornais da cidade publicaram os nomes dos 123 novos universitários da UFPA, Núcleo de Santarém (eram 23 homens e 100 mulheres), que foram aprovados para os três cursos oferecidos: LETRAS, ESTUDOS SOCIAIS e CIÊNCIAS NATURAIS'1.

A notícia publicada no Jornal de Santarém em 3 de abril de 1971 marcava a primeira ação considerada como expansão / interiorização da UFPA. O Núcleo de Educação era vinculado ao Centro de Educação (CE), conforme constava na Resolução n. 39/1970/Consun/UFPA, a qual estabelecia em seu Artigo 6" : 'Os Núcleos de Educação terão os professores e auxiliares designados pelo Reitor, mediante indicação do Diretor do Centro de Educação, de acordo com os cursos que estiverem sendo ministrados". (UFPA, 1970, p. 2).

Em Santarém, o Núcleo ficou sob a coordenação de Roberto Neves (1971-1982), professor da Faculdade de Matemática da UFPA, que também atuou ministrando aulas no Núcleo com outros professores, todos do quadro efetivo da UFPA e residentes em Belém. As aulas eram ministradas em períodos intervalares (férias escolares), em horário integral (turnos manhã e tarde) e destinavam-se apenas a professores em serviço. Essa primeira ação extensionista da UFPA em Santarém se entrelaça com a história do país, que vivenciava então o período conhecido como "milagre econômico", especificamente os anos de 1968/1973, caracterizados como o período em

${ }^{1}$ Notícia publicada no Jornal de Santarém em 3 de abril de 1971. 
que o Brasil alcançou níveis excepcionais de crescimento econômico, aumento do Produto Interno Bruto, inflação em declínio. Momento de "entusiasmos" para a população e "estratégias" para o governo, que passou a projetar "[...] a educação como formação de recursos humanos para o desenvolvimento econômico dentro dos parâmetros da ordem capitalista" (SAVIANI, 2008, p. 296), e, por conseguinte, a educação e o desenvolvimento se tornaram o "binômio condutor" das políticas de modernização do Estado brasileiro.

O governo federal, à medida que investia economicamente, em contrapartida exigia o retorno desses investimentos. Naquele contexto, a Amazônia brasileira e o estado do Pará, assim como os outros estados, foram convocados a contribuir para a consolidação do projeto nacional, projeto este que considerou o desenvolvimento científico e tecnológico "[...] como importante fator no progresso geral da nação e, inclusive, no tocante à distribuição de renda" (COLARES, 1998, p. 132); portanto, instrumento indispensável para o desenvolvimento econômico e social e tangível por meio da educação.

Os ideólogos militares identificaram claramente a importância que a educação poderia assumir, de maneira que caberia ao Estado, obrigatoriamente e sob pena de ser a principal vítima na hipótese de descaso, proporcionar um sistema de escolarização mínimo, mas eficiente, capaz de integrar toda a Nação em uma grande onda de civismo e patriotismo. (COLARES, 1998, p. 140)

A universidade adquiriu relevante importância ao ser abalizada como propulsora do avanço científico e tecnológico, entendido na época como indispensável ao desenvolvimento da sociedade. Com isso, inicia-se uma fase expansionista das universidades, tanto públicas quanto privadas (esta última em maior volume), cujo objetivo era auxiliar no desenvolvimento nacional. Para tanto, fezse necessário, por parte do governo federal, materializar as "medidas necessárias", por meio de encaminhamentos legais, como a reforma universitária de 1968, e, logo em seguida, a Lei n. $5.692 / 1971$, que fixou as diretrizes e bases para o ensino de $1^{\circ}$ e $2^{\circ}$ graus.

$\mathrm{Na}$ concepção de Colares (1998, p. 139), “[...] pela inexistência de cursos superiores em Santarém, a reforma universitária não teve repercussão, nem constituiu objeto de preocupação para professores e estudantes", ao contrário da outra reforma que, praticamente, significou uma nova LDB (de tanto que modificou a Lei n. 4.024, sancionada pelo presidente da República, João Goulart, em 20 de dezembro de 1961, após 13 anos do projeto ter sido enviado do executivo para a apreciação e votação de deputados federais e senadores).

O Núcleo e os cursos de licenciatura que passaram a funcionar foram precedidos por uma outra forma de presença, embora bem mais tímida, da UFPA em Santarém. Com base no DecretoLei n. 8.777, de 22 de janeiro de 1946 (BRASIL, 1946), que dispôs sobre o registro definitivo de professores de ensino secundário, foi realizado em 1968, em Santarém, o primeiro e único exame de suficiência, ação amparada pela Lei n. 4.024/1961 (BRASIL, 1961), que no Art. 117 assegurava: "Enquanto não houver número bastante de professores licenciados em faculdades de filosofia, e sempre que se registre essa falta, a habilitação a exercício do magistério será feita por meio de exame de suficiência" (BRASIL, 1961, p. 1). Essa alternativa foi adotada pelo MEC, em caráter emergencial, para tentar suprir a defasagem de professores do ensino secundário, principalmente nas regiões afastadas dos centros urbanos do país.

O exame de suficiência era destinado a legitimar a atuação de professores leigos, principalmente nas regiões afastadas dos centros urbanos, nos quais a expansão do ensino secundário estava em curso. A UFPA recorreu ao exame de suficiência como meio de prover a demanda de docentes para atuar no ensino secundário em Santarém. Os exames eram aplicados em conformidade com o que preconizava a Portaria Ministerial n. 478, de 24 de junho de 1954 (BRASIL, 1954). Consistiam na aplicação de prova escrita, prova didática e prova prática, se fosse 


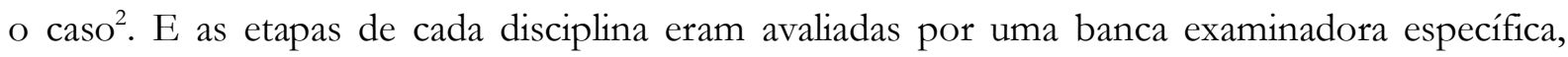
constituída por três professores.

Você fazia uma prova escrita de todas as disciplinas, depois uma prova da disciplina específica que você queria trabalhar, e só depois a prova didática, onde você devia ministrar uma aula para a banca formada por três professores da UFPA. No meu caso, que era para habilitar em Letras, fiz prova de gramática, literatura, texto, e outros conteúdos e ministrei a aula para os professores da Faculdade de Letras da UFPA. Não tinha um tempo determinado para a aula, alguns davam 15 minutos, outros 10 minutos, eu no caso foi apenas 5 minutos, e mandaram-me parar. Disseram: "tá bom!" Falaram "o senhor está autorizado a se retirar". Quando saí da sala, pensei: “Estou reprovado!" Pois tinha colegas que atuavam há mais de 20 anos e haviam sido reprovados. Depois me chamaram e falaram: "O senhor está aprovado, habilitado a ministrar a disciplina Língua Portuguesa, Inglês e Francês" (Entrevistado A) ${ }^{3}$.

Após a aprovação, o professor era autorizado a exercer o magistério da disciplina para a qual fora aprovado, em localidades onde não houvesse docentes diplomados por Faculdade de Filosofia ou onde a quantidade destes fosse insuficiente para atender a demanda do estabelecimento de ensino que desejasse contratá-lo. Geralmente, o registro dos candidatos era emitido com nota de validade exclusiva para a localidade ou região na qual ele poderia exercer o magistério; no entanto, havia a possibilidade de transferência para outra localidade ou região, mediante substituição do registro. Contudo, o número de professores que conseguiam o registro era bem reduzido.

No município de Santarém, o número de docentes que alcançaram essa certificação foi bem irrisório, em razão de inúmeros fatores, que vão desde a falta de conhecimento científico na disciplina à qual se desejava habilitar até a não recorrência dos exames no município, sendo, portanto, reduzido o número de professores certificados. As certificações, à medida que garantiram resultados positivos para os profissionais (melhoria salarial e reconhecimento de habilitação de nível superior), traziam alguns efeitos negativos para o ensino, haja vista que não ocorria processo formativo.

\section{O DESAFIO DE FORMAR PROFESSORES EM SERVIÇO}

A Resolução n. 39/1970/Consun/UFPA, que criou o Núcleo de Educação em Santarém, estabelecia em seus objetivos, no Art. 3:

a - formação de professores e especialistas, sem afastar os candidatos da área ou zona de suas atividades;

b - habilitação de professores e especialistas leigos, que estiverem em condições de serem aproveitados, mediante exame de suficiência;

c - melhoria das condições educacionais da área ou zona em que atuar;

d - qualificação e atualização do professorado de instituições de formação do magistério para o ensino de $1^{\circ}$ e $2^{\circ}$ grau. (UFPA, 1970, p. 1-2).

\footnotetext{
2 A prova prática era aplicada somente nos exames dos candidatos ao registro para o ensino de Física, Química, História Natural, Ciências Naturais, Economia doméstica e Trabalhos manuais. Essa prova tinha duração máxima de meia hora, para cada candidato, e constava de trabalhos práticos sobre assunto sorteado com a antecedência que a banca examinadora julgasse necessária em cada caso (BRASIL, 1954).

3 Professor certificado pelo Exame de Suficiência para o Magistério do Ensino Médio na disciplina Português ( $1^{\circ}$ ciclo), prestado em Santarém no mês de fevereiro de 1968. Entrevista realizada em 16 de fevereiro de 2019.
} 
Os objetivos elencados na Resolução n. 39/1970 convergiam para um propósito maior: "[...] contribuir na redução do déficit educacional e profissional do Estado" (COSTA e SOUZA, 2018, p. 82), porém restringiu a oferta aos professores atuantes na rede pública de ensino. A Resolução limitou a oferta à realização do Curso de Licenciatura Polivalente de $1^{\circ}$ Ciclo, destinado não somente a professores atuantes no ginásio (ensino fundamental) mas, também, com prerrogativa para lecionar no $2^{\circ}$ ciclo (ou colégio), enquanto não houvesse professores suficientes formados em quatro anos.

No Núcleo de Santarém, após os exames vestibulares, iniciaram-se em janeiro de 1971 as primeiras aulas das turmas de licenciatura em Letras, Estudos Sociais e Ciências Naturais, compostas de 123 novos universitários da UFPA, sendo 23 homens e 100 mulheres, todos atuantes na área de educação.

Os cursos ofertados no Núcleo de Santarém ("licenciatura curta") tiveram por objetivo "[...] preparar os professores das matérias: Português, Matemática, Geografia, História, Ciências e Didática Geral" (COLARES, 1998, p. 170). Funcionavam durante as férias escolares e destinavamse aos professores residentes no município. Contudo, "[...] a primeira turma apresentou-se bastante diversificada, contando com a presença de profissionais dos municípios vizinhos (Óbidos, Alenquer, Monte Alegre e Itaituba) e até de outros estados, inclusive Mato Grosso e Tocantins" $(\text { Entrevistado } \mathrm{A})^{4}$.

O fato de as aulas ocorrerem nas férias e de forma intensiva (manhã e tarde, e às vezes até à noite), tornava o ato de estudar bastante cansativo, entretanto, na visão de um dos estudantes da época, não chegava a ser desmotivador. Como o público discente era formado por professores residentes em diversas localidades, para alguns "[...] vir para cá era dispendioso por conta da distância, pois como eram de outros municípios, e até estados, e não havia qualquer tipo de ajuda, não tinha hospedagem aqui, era preciso ficar na casa de conhecidos, na casa dos outros..." (Entrevistado A). Essa situação de permanência na cidade agravava-se por vários fatores. Entre estes, havia o econômico, pois alguns professores recebiam menos de um salário mínimo, e havia ainda o tempo prolongado e integral do curso (era cansativo estudar integralmente todo o período de férias e depois retornar sem descanso para as salas de aulas). Havia, também, as dificuldades financeiras para a permanência na cidade.

Santarém vivia os efeitos decorrentes da fase desenvolvimentista que o país passava (décadas de 1970/1980), recebendo significativo número de trabalhadores com suas famílias, oriundos de outras cidades e regiões em busca de melhores "condições de vida" na Amazônia. Junto a esse fator, havia o elevado êxodo rural, o aumento do comércio e outras atividades, gerando aumento populacional e, por consequência, a demanda por serviços públicos.

$\mathrm{Na}$ década de 70 , intensificou-se a inversão populacional da zona rural para a zona urbana. Em 1960, do total de 92.144 habitantes do município de Santarém, apenas 24.498 residiam na zona urbana. No início dos anos 80 , do total de 191.950 habitantes, 80.293 formavam a população rural enquanto a população urbana contava 111.657 habitantes [...]. O novo quadro populacional gerava novas demandas por serviços públicos como educação, saúde, transportes, saneamento. (COLARES, 1998, p. 150-151)

Ainda segundo Colares (1998, p. 155), “[...] o grande aumento populacional registrado na cidade de Santarém, que em 1960 contava com 24.498 habitantes e em 1970 somava 51.009 habitantes, não encontrou o equivalente crescimento na rede de ensino”. Essa condição passava a

\footnotetext{
${ }^{4}$ Professor da rede pública estadual e estudante do Núcleo de Educação da UFPA em Santarém na década de 1970. Entrevista realizada em 16 de fevereiro de 2019.
} 
implicar a necessidade de formar professores para atender a demanda do município, principalmente em nível de segundo grau, em que a carência por profissionais com formação específica era maior, e o número de profissionais com formação superior, em Santarém, inexpressivo. Com isso, "[...] alunos que concluíam o segundo grau e que eram considerados 'bons' em determinadas disciplinas acabavam por iniciar as atividades de ensino logo após a conclusão do curso" (Entrevistado B) em razão da demanda estudantil e da ausência de professores com formação específica. Assim, na concepção de Costa e Souza (2018, p. 80), neste contexto “[...] a expansão da educação superior pública em nível de graduação tornou-se imperativa", competindo a esta a responsabilidade de formar e qualificar professores.

Mesmo existindo uma suposta política nacional em execução no país de formação de professores, criada a partir da Lei n. 4.024/1961, não havia recursos e planejamento adequado para as universidades realizarem essa formação. O governo federal, ao criar as licenciaturas de curta duração, cursos de caráter experimental e emergencial, priorizou "do mínimo por menos", isto é, o mínimo de qualificação necessária ao exercício da atividade docente pelo menor custo e tempo possíveis (NASCIMENTO, 2012).

Esses cursos eram ministrados com bastante precariedade, sem infraestrutura adequada, sem as mínimas condições para realização de pesquisa, em horário integral, o que ocasionava aos cursistas, professores em período de férias, o retorno imediatamente às salas de aula ao final dos módulos, sem nenhum período de descanso. Essas precariedades tornavam inviável o bom andamento das atividades. Contudo, não levaram a altos índices de evasão, haja vista os alunos verem naquele curso a possibilidade de qualificação profissional e de ganhos financeiros melhores. O conjunto dessas mesmas dificuldades, por sua vez, “[...] afastava novos pretensos aos cursos, tanto que no ano seguinte, das 120 vagas que a Universidade ofertou apenas 67 candidatos inscreveram-se, sendo que destes, 4 solicitaram a transferência para a capital do Estado". (COLARES, 1998, p. 170).

Saviani (2008, p. 297) destaca que as principais reformas implantadas durante o regime civilmilitar primaram por uma "[...] concepção produtivista da educação", incorporada à legislação do ensino e baseada em alguns pontos principais, como: princípios de racionalidade técnica, eficiência e produtividade, princípios estes que buscavam "[...] o máximo resultado com o mínimo dispêndio", ou seja, a valorização dos aspectos quantitativos em detrimento da qualidade do ensino. Fica evidente, portanto, que essas características eram inerentes aos cursos de licenciatura curta implantados nesse período. Utilizava-se o mínimo de investimentos em recursos, o mínimo de tempo para a formação e exigia-se o máximo em resultados quantitativos.

Nota-se, ainda, que os cursos obedeciam ao intuito a que se propuseram: "[...] formação rápida e generalista de professores para atenderem à demanda de alunos no país” (CHAUÍ, 1977, p. 151). Era necessário formar, portanto, professores de forma rápida e a baixos custos, com carga horária reduzida, processo formativo aligeirado e legitimado por uma política educacional que se preocupou mais em suprir a demanda de formação para o trabalho que a formação integral do profissional, conforme destaca a filósofa Marilena Chauí (1977) ao avaliar essa modalidade de formação.

O que é um professor curto? Um licenciado encurtado é curto em todos os sentidos: formação em tempo curto; a curto preço para a escola (mas a alto custo para o estudante), intelectualmente curto. Portanto, um profissional que dará aulas medíocres a baixo preço remunerado apenas pela hora-aula, sem condições

\footnotetext{
${ }^{5}$ Ex-professora da rede pública estadual (Escola Álvaro Adolfo na década de 1970) e estudante do Núcleo da UFPA em Santarém em 1973. Entrevista realizada em 16 de fevereiro de 2019.
} 
de prepará-las. Incapacitado para a pesquisa - por falta de formação anterior e de condições para cursar uma pós-graduação - é um professor dócil. Dócil às empresas porque é mão-de-obra farta e barata; dócil ao Estado porque não pode refletir face à sociedade e ao conhecimento. Com esta degradação do professor em termo sociais e intelectuais, trazida pela reforma, reduz-se o nível do ensino e prepara-se a morte da pesquisa. (CHAUÍ, 1977, p. 152)

Para Chauí (1977), o professor formado em um curso de curta duração tornava-se um docente limitado, um licenciado encurtado em todos os sentidos, sem formação para a pesquisa e para o ensino. Decerto, concordamos com a autora no que tange às limitações na formação desses profissionais, mas, no caso específico de Santarém, esses cursos possibilitaram "florescer" na cidade um pequeno grupo de educadores "qualificados" para atuar em níveis mais elevados de ensino (fato determinante para a implantação do curso regular de pedagogia da UFPA em Santarém, na década de 1980, conforme veremos nas próximas subseções), além de obter ganhos financeiros melhores, reconhecimento profissional e até ver o nascimento de um relevante grupo de intelectuais santarenos, conforme demonstra a exposição a seguir.

Depois do curso, além de podermos atuar como professores habilitados ao ensino do segundo grau, também passamos a ser gratificados financeiramente melhor. Na época, fiz o concurso do Estado, em 1973, e ao ser habilitada no concurso já entrei como professora de segundo grau, isso porque quando concluí o ensino médio, fui convidada a substituir uma professora que havia viajado, e já comecei a atuar. A licenciatura curta me possibilitou isso, ser enquadrada como professora com qualificação em nível superior, ter um salário melhor, pois naquela época a Prefeitura pagava menos de um salário mínimo. Foi muito bom acreditar na educação superior naquela época, pois nos possibilitou muitas vantagens pessoais e profissionais, o reconhecimento. Era um pequeno grupo daqui que tinha essa formação, pois como tinha colegas de outras localidades, eles voltaram para suas cidades, como uma colega, a Antônia Gonçalves que era de Goiás, outro estado. Lá ela era diretora e precisava se qualificar. Os que ficaram aqui contribuíram muito, inclusive depois com a UFPA, como professores contratados (Entrevistada B).

Em contradição à exposição anterior, são perceptíveis, também, na fala dos entrevistados, as fragilidades do curso e a percepção destes quanto ao fato de aquela formação ser aquém de suas expectativas.

Dizem que a licenciatura curta acabou porque pegou mal. Chamavam a licenciatura curta de bicó, falavam: "Ah, vocês são da bicó é?" (Risos). (Entrevistado A)

Quando concluímos a licenciatura curta recebemos um certificado nos habilitando para ministrar essas disciplinas, um período, depois foi avisado que teríamos a complementação, a licenciatura plena, e de certo veio. Mas daquele grupo - que era uma média de mais de 100 alunos —, não voltaram todos. Diria sem precisão o número, mas foi uma média de 24 ou 25 alunos que concluíram o curso de licenciatura plena. Os motivos podem ter sido uma série de fatores, mas alguns colegas confessaram que já estavam habilitados, então não viam por que voltar e fazer a complementação... (Entrevistado B).

Colares (1998) e Costa (2014) apontam que as limitações estruturais e pessoais contribuíram para o arrefecimento da oferta dos cursos por parte da UFPA, fato comprovado pela fala dos informantes que atribuem, além desses motivos, o estilo "qualificador" dos cursos, em que a 
formação era restrita à qualificação de mão de obra para o trabalho. Essa questão levou alguns estudantes ao entendimento de que a licenciatura curta os habilitava ao nível desejado, não demandando a complementação em licenciatura plena; e, por consequência, naquele momento, o entendimento errôneo por parte da instituição universitária, que havia realizado a sua função.

A redução do número de candidatos aos cursos de licenciatura ofertados pela UFPA no Núcleo de Santarém, no início da década de 1970, não mereceu avaliação adequada por parte da gestão superior da Universidade, que considerou a diminuição da demanda como reflexo do desinteresse da sociedade santarena pela educação superior.

Ao invés de servir como indicativo para que fossem apuradas as verdadeiras causas do problema, resultou no arrefecimento da oferta, sob alegação de que os estudantes santarenos não manifestavam interesse por estudos superiores e nem havia ainda número que justificasse a continuidade do investimento naquele setor. (COLARES, 1998, p. 171)

A intepretação equivocada por parte da gestão superior da UFPA quanto à demanda dos cursos superiores ofertados em Santarém, aliada à ausência de projetos para a interiorização da Universidade, resultou no retorno à centralização de suas ações na capital do estado, constituindo assim um retrocesso, e um novo período de ausência da oferta de educação superior no município de Santarém.

\section{O DESAFIO DE INSISTIR E OUSAR}

Em 1979, se intensificaram as articulações internas na UFPA para a retomada das atividades do Núcleo, por pessoas mais próximas da administração superior e que buscavam fortalecer a imagem dos pretensos candidatos (FONTES, 2018). A interiorização já era apresentada como bandeira de campanha, porém, o fracasso das ações iniciadas em 1971 constituía obstáculo. Na tentativa de minimizar a articulação de possíveis opositores, o reitor Aracy Amazonas Barretto (1977-1981) autorizou, ainda no ano de 1979, os preparativos para a reativação do Núcleo de Educação de Santarém, para a oferta da complementação dos cursos de licenciatura curta e licenciatura plena entre 1980 e 1983. Notícia veiculada no Jornal de Santarém em 7 de março de 1981 aponta o início de uma nova oferta de cursos em Santarém, no dia 5 de dezembro de 1980, estendendo-se até 13 de março de 1981 e retornando no mês de julho daquele ano. Ou seja, o Núcleo continuava a ofertar apenas cursos para professores em período de férias escolares.

Persistiram no Núcleo de Educação de Santarém os problemas vivenciados anteriormente, quanto à infraestrutura inadequada, inexistência de apoio à pesquisa, e muitas dificuldades administrativas. A relação política entre a gestão superior da UFPA e o gestor municipal Antônio Guerreiro Guimarães, aliado do governador do Estado, Alacid da Silva Nunes (1979-1983), havia ficado estremecida, uma vez que este último havia rompido com Jarbas Gonçalves Passarinho ${ }^{6}$, político paraense de expressão nacional que gozava de muita influência no MEC e com a toda a cúpula militar. Jarbas era antigo "padrinho político" do governador do estado. O rompimento se deu em março de 1981, após longo período de desentendimento. Quando das tratativas para a implantação de um curso superior regular em Santarém já havia outro quadro político. O prefeito Ronan Liberal estava alinhado com a cúpula militar do governo federal e tinha trânsito junto à reitoria da UFPA, o que favoreceu a tessitura do convênio UFPA/SUDAM/Prefeitura, com a

\footnotetext{
${ }^{6}$ Militar e político nascido no estado do Acre, fez carreira política no Pará, tendo sido governador. Ocupou também o posto central em vários ministérios: do Trabalho; da Educação; da Previdência Social; e da Justiça, além de ter sido presidente do Senado Federal.
} 
destinação de 135 vagas em três turmas, sendo uma no período vespertino e duas no período noturno.

O primeiro curso superior regular ofertado pela UFPA em Santarém iniciou-se em 1983, orientado pelo Parecer n. 252/1969-CFE e pela Resolução CFE n. 2/1969, para a formação de Especialistas em Educação (Administração Escolar; Supervisão Escolar, Inspeção Escolar e Orientação Educacional) (COSTA e SOUZA, 2018, p. 60). As normas de funcionamento seguiram os princípios orientadores da Lei n. 5.540/1968 - Lei da Reforma Universitária.

Ronan Liberal, diante da vitória de Jader Fontenelle Barbalho (PMDB) para o governo do estado nas eleições de 1982, buscava fortalecimento político para permanecer no cargo. O convênio entre UFPA, Sudam e PMS e o curso superior dele resultante representa, naquele contexto, um acontecimento positivo e estratégico para suas pretensões. Com aprovação da Câmara Municipal, disponibilizou para a UFPA o terreno e o prédio de uma escola recém-construída e que ainda não estava em uso, a Escola Municipal Dr. Everaldo de Sousa Martins, para que nela funcionasse o curso de pedagogia e fossem realizadas as demais atividades. Disponibilizou, também, servidores para apoio técnico, material de limpeza e um ramal telefônico. O prédio possuía 15 salas de aula e fora instalado ocupando parte de um antigo campo de futebol, denominado Morango, o qual gradativamente foi sendo tomado por novas instalações físicas.

Pelas cláusulas do convênio caberia à Sudam a responsabilidade por repasses financeiros à UFPA, a serem utilizados nas despesas com deslocamento dos professores (passagens e diárias) no trecho Belém-Santarém-Belém, e a estadia enquanto permanecessem ministrando aulas em Santarém; cabia à UFPA "[...] cuidar do bom funcionamento do curso, conforme o projeto pedagógico" (COLARES, 2019, p. 34) aprovado em $1^{\circ}$ de março de 1983, pela Resolução n. 920, do Conselho Superior de Ensino da UFPA. A Prefeitura se responsabilizava pelo apoio logístico com pessoa de secretaria e de apoio, assim como materiais para limpeza e outras eventualidades. Desse modo, por meio do convênio UFPA/Sudam/PMS, estabeleceram-se os critérios para o funcionamento do primeiro curso superior público regular em Santarém, e que era a primeira oferta fora da sede da UFPA desde a sua criação. O ingresso se deu pela realização de exame vestibular aberto, o qual teve um acentuado número de inscritos (média de 12 candidatos por vaga), dada a demanda reprimida existente e a possibilidade de os pretendentes realizarem um curso em período letivo regular.

\section{CONSIDERAÇÕES FINAIS}

A UFPA “saiu” de Belém para o interior do Estado, sendo a cidade de Santarém a primeira a ser contemplada com a implantação de um Núcleo de Educação, o qual foi instalado em uma escola da rede estadual, em caráter precário e experimental, e ofertando cursos para professores, em férias, na modalidade licenciatura curta, que existia na época. Dito assim, parece simples, mas o "sair da capital", além da demora, foi permeado de muitos fatores, alguns dos quais foram apresentados com mais detalhes. Acima de tudo prevaleceu a ousadia de alguns dirigentes, mesmo se impulsionados por interesses políticos de viés eleitoreiro, identificáveis de forma mais expressiva em épocas de campanhas políticas para eleições tanto na reitoria da Universidade quanto para cargos do Executivo e do Legislativo das diversas esferas de governo.

A presença inicial da Universidade (UFPA) ocorreu em 1968, por decorrência da aplicação do primeiro e único exame de suficiência realizado pela UFPA no munícipio. A instituição assumiu, com a realização do exame, o papel de "certificadora" e abreviou qualquer expectativa quanto à expansão da Universidade naquele momento, haja vista tal ação ser amparada pela Lei n. 4.024/1961 (BRASIL, 1961), constituindo alternativa adotada pelo MEC, em caráter emergencial, 
para tentar suprir a defasagem de professores do ensino secundário, principalmente nas regiões afastadas dos centros urbanos do país. Todavia, a mera aplicação de exames não supria qualquer defasagem em termos de formação ou qualificação do professor, e sim apenas "rotulava" alguns como aptos e outros como não aptos a lecionar determinada disciplina, conforme os níveis de ensino.

Não muito diferente daquela primeira forma de presença, a instalação do Núcleo de Educação da UFPA em Santarém (1971) limitou-se apenas à qualificação profissional de um público restrito, até o ano de 1976, quando as primeiras turmas concluíram sua formação em licenciatura curta. Podemos inferir, entretanto que, a partir da implantação do Núcleo e sua rápida desativação, houve o despertar da sociedade local quanto à necessidade de mobilização em torno do acesso à universidade pública. A esse respeito, os entrevistados foram unânimes em afirmar que os egressos das primeiras turmas de licenciatura curta ofertadas pela UFPA em Santarém foram imprescindíveis para o processo de reativação do Núcleo de Educação na década de 1980, e que, mesmo diante da ausência de registros que expressem o protagonismo dessas pessoas, é notório que a mobilização social constituiu importante elemento impulsionador.

A mobilização da sociedade santarena em torno da permanência do Núcleo da UFPA revela uma das principais rupturas no campo histórico educacional, no decorrer daquele contexto, com o retorno à centralização das ações da UFPA na capital do estado e, por conseguinte, um retrocesso quanto à oferta de educação superior no município de Santarém. Segmentos representativos da população, ao vivenciarem a retomada das atividades da UFPA no início da década de 1980, com a reativação do Núcleo, começam a participar mais ativamente do processo reivindicatório do ensino superior público.

\section{REFERÊNCIAS}

ARAGÓN, Luís Eduardo. Ciência e educação superior na Amazônia: desafios e oportunidades de cooperação internacional. Belém: Associação de Universidades Amazônicas (UNAMAZ): Núcleo de Altos Estudos Amazônicos (NAEA), 2001.

BRASIL. Atos do Governo. Decreto-Lei n. 8.777, de 22 de janeiro de 1946. Dispõe sobre o registro definitivo de professores de ensino secundário no Ministério da Educação e Saúde. Rio de Janeiro: Diário Oficial dos Estados Unidos do Brasil. Ano LXXXV, n. 20, Seção 1, 1946h. Publicação original disponível em: http://www.jusbrasil.com.br/diarios/2190192/pg-15-secao-1-diariooficial-da-uniao-dou-de-24-01-1946/pdfView. Acesso em: 21. fev. 2019.

BRASIL. Lei n. 5.692, de 11 de agosto de 1971. Fixa diretrizes e bases para o ensino de $1^{\circ}$ e $2^{\circ}$ graus, e dá outras providências. Diário Oficial da União, Brasília, DF, 12 ago. 1971.

BRASIL. Lei n. 4.024, de 20 de dezembro de 1961. Fixa as Diretrizes e Bases da Educação Nacional. Presidência da República/Casa Civil/Subchefia para Assuntos Jurídicos. Disponível em: http://www.planalto.gov.br/CCIVil 03/leis/L4024.htm. Acesso em: 21. fev. 2019.

BRASIL. Ministério da Educação e Cultura. Portaria Ministerial n. 478, de 24 de junho de 1954. Dispõe sobre o registro dos licenciados por Faculdades de Filosofia para exercício do magistério no curso secundário. Revista Brasileira de Estudos Pedagógicos (RBEP). Rio de Janeiro, v. XXII; n. 55, jul./set. 1954, p. 192-194.

CARVALHO, Edneia Nascimento. A interiorização do ensino superior na Amazônia: o caso de Santarém no oeste do Pará - 1985 a 2010. 2014. 267f. Tese (Doutorado) - Programa de Pós-Graduação em Geografia do Centro de Ciências e Tecnologia da Universidade Estadual do Ceará, Fortaleza, 2014. 
CHAUÍ, Marilena. Folha de São Paulo, 6 jul. 1977. In: PILETTTI, Nelson. História da Educação no Brasil. São Paulo: Editora Ática, 1990.

COLARES, Anselmo Alencar. Sociedade e educaşão em Santarém - PA: estudo do período em que o município foi de segurança nacional (1969/1984). 1998. Dissertação (Mestrado) - Universidade Estadual de Campinas, Faculdade de Educação, Campinas, 1998. Programa de Pós-Graduação em Educação. Disponível em: http://repositorio.ufpa.br/ispui/handle/2011/9236. Acesso em: 13 mar. 2019.

COLARES, Anselmo Alencar. Ensinar e aprender: história e memória. Curitiba: CRV, 2019.

COSTA, Maria Raimunda Santos da. As repercussões da interiorização da UFP A no trabalho dos docentes da rede estadual de ensino nas décadas de 1980 e 1990. 2014. 339 f. Tese (Doutorado) - Universidade Federal do Pará, Instituto de Ciências da Educação, Belém, 2014. Programa de Pós-Graduação em Educação.

COSTA, Maria. Raimunda Santos da; SOUZA, Rosana Ramos de. A trajetória do curso de Pedagogia da UFPA na região Oeste do Pará - da década de 1970 a 2009: instalação e consolidação. Linguagens, Educação e Sociedade, Teresina, ano 23, Edição Especial, dez. 2018. Revista do Programa de PósGraduação em Educação da UFPi. Disponível em: https://doi.org/10.26694/les.v1i1.7720. Acesso em: 29 jan. 2019.

FONTES, Edilza Joana. Comissão da Verdade na Universidade Federal do Pará: a criação de um acervo digital com testemunhos de violações dos direitos humanos. História Oral, v. 21, n. 2, p. 109129, jul./dez. 2018. Disponível em: http://memorialcesarleite.com.br/storage/pesquisas/tbyuadVaBMappAaVCUXUBxENEhcctU WMnn4GA4M8.pdf. Acesso em: 12 set. 2019.

NASCIMENTO, Thiago Rodrigues. A criaģão das licenciaturas curtas no Brasil. Revista HISTEDBR Online, v. 12, n. 45, 2012. Disponível em: http://www.histedbr.fe.unicamp.br/revista/edicoes/ 45/doc01 45.pdf. Acesso em: 19 fev. 2019.

SAVIANI, Dermeval. O legado educacional do Regime Militar. Caderno CEDES [online]. 2008, v. 28, n. 76, p. 291-312. Disponível em: http://dx.doi.org/10.1590/S0101-32622008000300002. Acesso em: 28 maio 2018.

SEVERINO, Antonio Joaquim. Educação e universidade: conhecimento e construção da cidadania. Interface - Comunic, Saúde, Educ, v. 6, n. 10, p. 117-124, fev. 2002. Disponível em: http://www.scielo.br/pdf/icse/v6n10/15.pdf. Acesso em: 12 maio 2018.

SEVERINO, Antônio Joaquim. O ensino superior brasileiro: novas configurações e velhos desafios. Educar, Curitiba, n. 31, p. 73-89, 2008. Editora UFPR Educ. rev. [online]. Disponível em: http://www.scielo.br/scielo.php?pid=S0104-40602008000100006\&script=sci abstract\&tlng=pt. Acesso em: 12 maio 2018.

ROMANELLI, Otaíza O. História da Educação no Brasil (1930/1973). 27. ed., Petrópolis: Vozes, 2002.

UFPA. Resolução n. 39/Consun/UFPA, de 14 de outubro de 1970. Cria os Núcleos de Educação em Santarém em Macapá, para a realização do Curso de Licenciatura Polivalente de $1^{\circ}$ Ciclo. Disponível em: http://sege.ufpa.br/boletim_interno/downloads/resolucoes/consun/1970/39\%20Cria $\% 20 \mathrm{Nucl}$ eos $\% 20$ de $\% 20$ Educacao.pdf. Acesso em: 3 out. 2019. 
DOI: https://doi.org/10.12957/teias.2020.49687

Submetido em marco 2020. Aprovado em abril 2020.

\section{Informações do(a) autor(a)}

Francisca Márcia Lima de Sousa

Pesquisadora/Técnica em Educação da Universidade Federal do Oeste do Pará (UFOPA)

E-mail: marciaufopa@gmail.com

ORCID: https://orcid.org/0000-0002-0588-6651

Link Lattes: http:/ /lattes.cnpq.br/4351608442830835

Anselmo Alencar Colares

Professor Titular da Universidade Federal do Oeste do Pará (UFOPA)

E-mail: anselmo.colares@gmail.com

ORCID: https://orcid.org/0000-0002-1767-5640

Link Lattes: http://lattes.cnpq.br/1107767923215438 